Atmos. Chem. Phys. Discuss., 9, 21941-21958, 2009 www.atmos-chem-phys-discuss.net/9/21941/2009/ (C) Author(s) 2009. This work is distributed under the Creative Commons Attribution 3.0 License.
Atmospheric

Chemistry and Physics Discussions

This discussion paper is/has been under review for the journal Atmospheric Chemistry and Physics (ACP). Please refer to the corresponding final paper in $A C P$ if available.

\title{
Atmospheric electric field anomalies associated with solar flare/coronal mass ejection events and solar energetic charged particle "Ground Level Events"
}

E. A. Kasatkina ${ }^{1}$, O. I. Shumilov ${ }^{1}$, M. J. Rycroft ${ }^{2}$, F. Marcz ${ }^{3}$, and A. V. Frank-Kamenetsky ${ }^{4}$

${ }^{1}$ Inst. of North Industrial Ecology Problems, Kola Science Center of RAS, 184209 Apatity, Russia ${ }^{2}$ CAESAR Consultancy, 35 Millington Road, Cambridge CB3 9HW, UK

${ }^{3}$ Geodetic and Geophysical Research Institute of the Hungarian Academy of Sciences, 9401 Sopron, POB 5, Hungary

${ }^{4}$ Arctic and Antarctic Research Institute, 38 Bering Street, 199397, St.-Petersburg, Russia

Received: 18 May 2009 - Accepted: 9 October 2009 - Published: 20 October 2009

Correspondence to: O. I. Shumilov (oleg@ aprec.ru)

Published by Copernicus Publications on behalf of the European Geosciences Union.

ACPD

Solar flares/CMEs, Ground Level Events and atmospheric disturbances

E. A. Kasatkina et al.

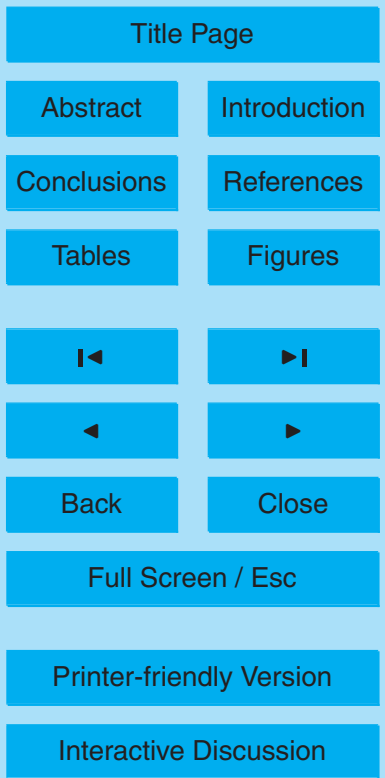




\section{Abstract}

We discuss the fair weather atmospheric electric field signatures of three major solar energetic charged particle events which occurred in on 15 April 2001, 18 April and 4 November, and their causative solar flares/coronal mass ejections (SF/CMEs). Only 5 the 15 April 2001 shows clear evidence for $E_{z}$ variation associated to SF/CME events and the other two events may support this hypothesis as well although for them the meteorological data were not available. All three events seem to be associated with relativistic solar protons (i.e. protons with energies $>450 \mathrm{MeV}$ ) of the Ground Level Event (GLE) type. The study presents data on variations of the vertical component of 10 the atmospheric electric field $\left(E_{z}\right)$ measured at the auroral station Apatity (geomagnetic latitude: $63.8^{\circ}$, the polar cap station Vostok (geomagnetic latitude: $-89.3^{\circ}$ ) and the middle latitude stations Voyeikovo (geomagnetic latitude: $56.1^{\circ}$ ) and Nagycenk (geomagnetic latitude: $47.2^{\circ}$ ). A significant disturbance in the atmospheric electric field is sometimes observed close to the time of the causative solar flare; the beginning of the electric field perturbation at Apatity is detected one or two hours before the flare onset and the GLE onset. Atmospheric electric field records at Vostok and Voyeikovo show a similar disturbance at the same time for the 15 April 2001 event. Some mechanisms responsible for the electric field perturbations are considered.

\section{Introduction}

20 Solar flare (SF) and solar cosmic ray (SCR) effects on variations of the fair weather atmospheric electric field $\left(E_{z}\right)$ have been studied in a number of papers (Cobb, 1967; Reiter, 1969; Markson, 1971, 1978; Olson et al., 1978; Reagan et al., 1983; Goldberg, 1984; Moiseev et al., 1993; Zadorozhny et al., 1994; Sheftel et al., 1994; Rycroft et al., $2000)$. Solar protons of high energies ( $>450 \mathrm{MeV}$ ) lead to different changes of electric 25 properties in the atmosphere. For example, Holzworth and Mozer (1979) and Reagan et al. (1983) reported a reduction of the vertical electric field (by up to 90\%) and an

Solar flares/CMEs, Ground Level Events and atmospheric disturbances

E. A. Kasatkina et al.

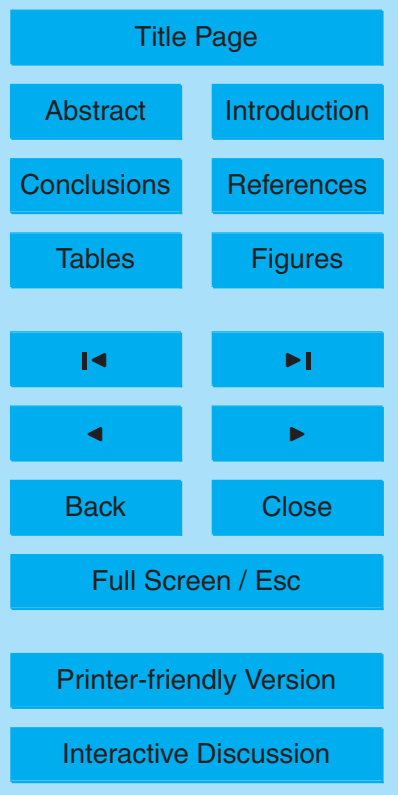


increase of atmospheric conductivity at $30 \mathrm{~km}$ (balloon altitudes) during the great solar proton event of the Ground Level Event (GLE) type on 4 August 1972. Such a response is to be expected from the relationship between the vertical atmospheric current density $j_{z}$, conductivity $\sigma$ and vertical electric field $E_{z}$ :

$5 j_{z}=\sigma E_{z}$,

On the other hand, Holzworth et al. (1987) and Zadorozhny et al. (1994) detected an increase of the vertical component of the electric field in the stratosphere and low mesosphere with a simultaneous increase of conductivity during two other GLEs (16 February 1984 and 19 October 1989, respectively). The existence of such large stratospheric 10 and mesospheric electric fields may be related to aerosol layers (Goldberg, 1984; Holzworth et al., 1987; Zadorozhny et al., 1994; Rycroft et al., 2000). Relativistic solar protons penetrating the atmosphere may affect the aerosol layer through ionization and ion nucleation processes (Arnold, 1982; Hofmann and Rosen, 1983; Goldberg, 1984). Shumilov et al. (1996) detected an increase in aerosol concentration up to $50 \%$ at $20 \mathrm{~km}$ altitude at high latitudes following the 16 February 1984 GLE. Moreover, the energetic charged particle precipitation may "short out" such existing mesospheric and stratospheric electric fields, producing either an increase or decrease of $E_{z}$ (Hale and Croskey, 1979; Zadorozhny et al., 1994). In particular, in Holzworth et al. (1987), Zadorozhny et al. (1994), Zadorozhny and Tyutin (1998) and Kasatkina and Shumilov 20 (2005) it was shown that the increase of the vertical component of the electric field strength during a GLE event is possible if the total aerosol change increases with the ion pair production rate increase more than that of the conductivity. For example, this phenomenon may be considered in the charged aerosol gravitational sedimentation physical mechanism (Aikin and Maynard, 1990; Zadorozhny et al., 1994; Zadorozhny 25 and Tyutin, 1998).

Major GLEs are rare events. Since 1980, three major GLEs occurred in 1981, two in 1982, one in 1984, seven in 1989, four in 1990, two each in 1991 and 1992, one in 1997, three in 1998, one in the millennium year 2000, five in 2001 and two in 2003 (data available at the Oulu Cosmic Ray Station website at http://cosmicrays.oulu.fi/GLE.html.

Solar flares/CMEs, Ground Level Events and atmospheric disturbances

E. A. Kasatkina et al.

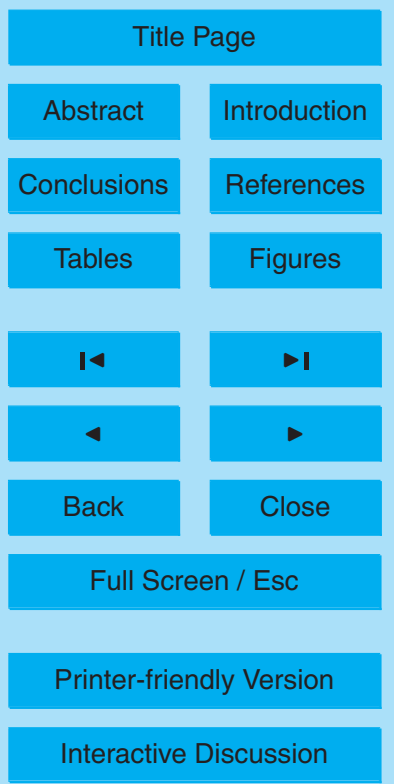


Measurements of $E_{z}$ are also rather rare. Data are available from Nagycenk in Hungary (geomagnetic latitude: $47.2^{\circ}$ ) since 2001, from Voeikovo in Russia (geomagnetic latitude: $56.1^{\circ}$ ) since 2001, from Apatity on the Kola Peninsula (geomagnetic latitude: $63.8^{\circ}$ ) from 2001 to 2002, and at the Antarctic Vostok station (geomagnetic latitude: $5-89.3^{\circ}$ ) from 2001 to 2002 . In this paper, the results of $E_{z}$ measurements are presented for three major GLEs (on 15 April, 18 April, and 4 November 2001) at different latitudes; data from Apatity, Vostok, Voeikovo and Nagycenk are presented. We are not aware of any other similar $E_{z}$ data being available during 2001 from other stations.

\section{Results}

10 Only five GLEs have been detected in 2001. Unfortunately, fair weather conditions occurred only for three of them. These three events are all associated with coronal mass ejections (CMEs) according to data from the Large Angle and Spectroscopic Coronograph (LASCO) on board the Solar Heliospheric Observatory (SOHO). The solar flare and CME onset times, peak times and properties of these events are summarized in 15 Table 1.

In Fig. 1 the $E_{z}$ component at the four stations, variations of the solar X-ray intensity and of the 1-min integral fluxes of energetic charged particles above a threshold energy observed by GOES-8 (data are available at the GOES website at http://rsd.gsfc.nasa. gov/goes) are shown for the 15 April 2001 GLE event. It is seen that vertical electric field variations at Apatity became more irregular with jumps (up to $\sim 1000 \mathrm{~V} / \mathrm{m}$ in ten minutes) approximately two hours before the GLE event onset at 14:10 UT according to the neutron monitor data (Poirier and D'Andrea, 2002) and $1.5 \mathrm{~h}$ before the X-ray flare of magnitude $X 14$. The corresponding optical flare on the Sun occurred in the region 9415 located at $20^{\circ} \mathrm{S}, 85^{\circ} \mathrm{W}$ at 13:19 UT (Nitta et al., 2003), at which time $E_{z}$ was $\sim-1000 \mathrm{~V} / \mathrm{m}$.

After the GLE event onset the electric field changed only slowly, and was generally $<300 \mathrm{~V} / \mathrm{m}$. Another jump in $E_{z}$ (to $-1000 \mathrm{~V} / \mathrm{m}$ ) occurred at $\sim 19: 40 \mathrm{UT}$ at the end of

Solar flares/CMEs, Ground Level Events and atmospheric disturbances

E. A. Kasatkina et al.

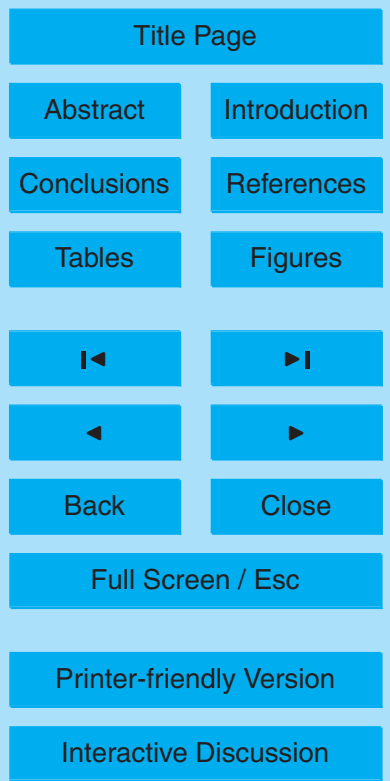

\section{4}


the GLE event according to the neutron monitor data (Poirier and D'Andrea, 2002). We have no idea about the causes of this second spike in $E_{z}$. However, we note that, at the same time ( 19:00 UT), an increase of solar proton ( $>1 \mathrm{MeV}$ and $>10 \mathrm{MeV}$ ) fluxes occurred. Although LASCO/C2 data show a very high background due to the 5 main eruption at 14:06 UT, the combined EIT/C2 difference images movie shows a brightening in EIT on the West limb at 18:04 UT, most probably from the same region of the 14:06 UT event. Ejection is also seen in C2 starting between 19:00 and 19:30 UT mainly on the south, but from 20:47 UT the ejection is also seen spread all around the West limb. The second jump seen at 19:40 UT in the electric field may be related to this 10 later event. This would also agree with the variation of the field detected at Voeikovo starting at about 19:00 UT. From Fig. 1, for the 15 April 2001 event, there are associated effects in the atmospheric electric field at middle latitudes (Voeikovo) and in the polar cap (Vostok). In general, the $E_{z}$ changes started up to $2.5 \mathrm{~h}$ before the SF and more before the corresponding GLE event.

It is well known that local meteorological factors (wind speed, temperature) may cause considerable changes in $E_{z}$. It was carried out the analysis of the wind speed variations at Vostok and Apatity for the period investigated. It turned out that the wind speed had been nearly constant since early on 14 April 2001, typically between 5 and $6 \mathrm{~m} / \mathrm{s}$, at Vostok station. At Apatity, there was a smooth increase of wind speed on the morning 15 April 2001, but for the period of interest the wind speed was generally $<5 \mathrm{~m} / \mathrm{s}$. Such wind speed values are not expected to lead to significant variations of atmospheric electric field (Daniljchenko et al., 1978). Unfortunately, there is no meteorological information at Nagycenk and Voeikovo. Therefore, a negative $E_{z}$ value $(-100 \mathrm{~V} / \mathrm{m})$ observed at Voeikovo in first half of day is more probably to be explained by the influence of local effects. However, considerable $E_{z}$ changes observed on the background of this negative value coincide with relative $E_{z}$ changes at Apatity and Vostok. We suppose these changes to be related to extraterrestrial influence strongly expressed at high latitudes. Nagycenk $E_{z}$ data were taken from the tables of hourly averages determined for quiet or slightly-disturbed conditions and published in the

Solar flares/CMEs, Ground Level Events and atmospheric disturbances

E. A. Kasatkina et al.

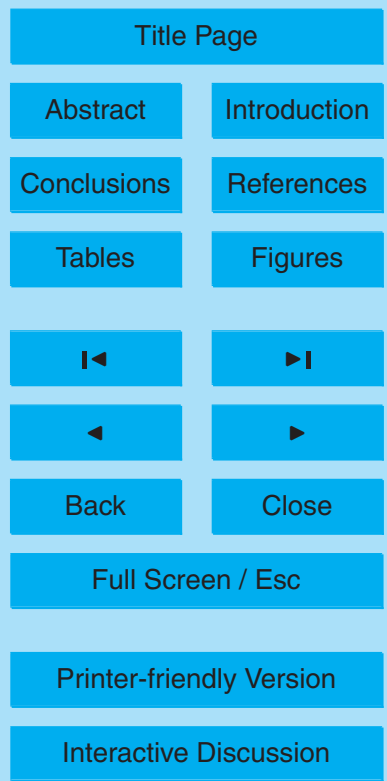


periodically-issued Observatory Reports (Marcz and Harrison, 2003). A low mean value of $E_{z}(\sim 30 \mathrm{~V} / \mathrm{m})$ being typical for the station seems to be connected to a longterm downwards trend in the Nagycenk $E_{z}$ (Marcz and Harrison, 2003).

Figures 2 and 3 show $E_{z}$ variations at Apatity and GOES-8 data for two other major 5 GLEs (18 April 2001 and 4 November 2001), associated with large solar flares (C2 and $\mathrm{X} 1$ ) originating from the Sun's western hemisphere (see Table 1). Again, an increase in $E_{z}$ occurred approximately one hour (on 18 April) and 20 min (on 4 November) before the flare onset, and lasted 7 and $2 \mathrm{~h}$, respectively. However, it should be noted that the pre-flare increase in $E_{z}$ on 18 April may be associated with the storm sudden 10 commencement (SSC) which occurred at 00:40 UT. No $E_{z}$ data from Vostok, Nagycenk and Voeikovo for 18 April and 4 November 2001.

\section{Discussion}

Processes of solar charged particle injection into the heliosphere are controlled by solar coronal structures. The maximum injection takes place from the region coinciding with 15 the magnetic active region where the solar flare happened. Outside the active region the solar proton injection is much weaker. The solar flare on 15 April 2001 appeared in a region close to the western limb of the Sun where one would expect good magnetic connection between the flare site and the Earth along a spiral interplanetary magnetic field line. These solar flares are characterized by the prompt arrival of energetic particles (Gosling, 1993). For the 15 April 2001 GLE we calculated the heliolongitude of the footprint of the Sun-Earth line of force $\Phi$ using methods developed by Nolte and Roelof (1973a, b):

$\Phi=\left(\Omega r / V_{s w}\right)$,

where: $r$ is the distance between the Earth and the Sun, $\Omega$ is the angular velocity of the Sun's rotation ( $\Omega=14.3^{\circ} /$ day), and $V_{s W}$ is the solar wind speed.

Solar flares/CMEs, Ground Level Events and atmospheric disturbances

E. A. Kasatkina et al.

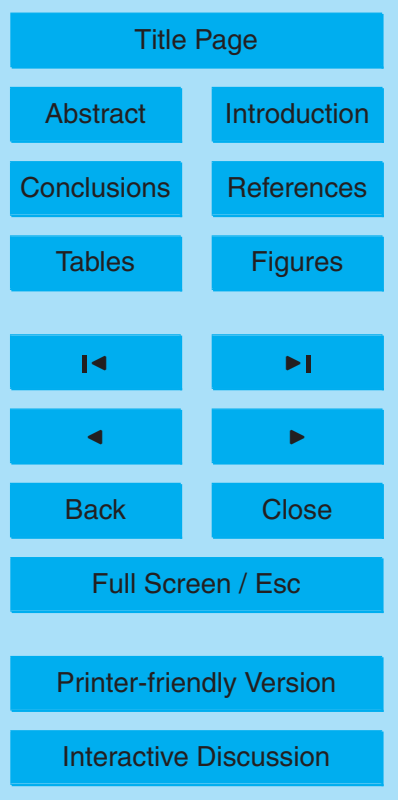


The result of the calculation $\left(\Phi=49.6^{\circ}\right)$ and an analysis of the solar magnetic field map (Solar Geophysical Data, 2001) for the 15 April 2001 event have shown that the flare and the corresponding footprint of the Sun-Earth line of force were located within the same active region. Similar calculations for the 4 November 2001 SF/CME event 5 show a different situation: the footprint of the magnetic line was outside the active magnetic region where the flare took place.

All three SF/CMEs are accompanied by atmospheric electric field changes at the auroral observatory of Apatity. For the 15 April 2001 event, $E_{z}$ variations were detected in three different zones of magnetic latitude (polar cap, auroral zone and middle lati10 tudes). An investigation of $E_{z}$ records from Nagycenk (Hungary) (geomagnetic latitude: $47.2^{\circ} \mathrm{N}$; L 2) did not demonstrate any variations associated with GLEs, presumably a latitudinal effect (Marcz, 1976; Marcz and Harrison, 2003). It should also be taken into account that two of the GLEs considered (15 April and 18 April 2001) occurred during strong ( $>35 \%$ according to the auroral neutron monitor data) Forbush decreases 15 (FDs) of galactic cosmic rays (data available at the Oulu Neutron Monitor website at http://spaceweb.oulu.fi/projects/crs). Thus the GLE effects in the atmospheric electric field at middle latitudes may be masked by FDs (Marcz, 1997).

Another interesting phenomenon is the variation of $E_{z}$ observed before SF/CME onset. In some published works (Reiter, 1969; Olson et al., 1978; Kobrin et al., 1982; Moiseev et al., 1993; Goshdzhanov et al., 1993) it had been shown that solar flare precursors influenced some geophysical and meteorological parameters at the Earth before the flare onset. In particular, one or two days before the flare appearance, there may be some changes in the intensity of the $H_{\alpha}$ line, the creation of loop prominences, quasi-periodic fluctuations of radio-emission with periods of 20-200 min, and 25 pulsations of geomagnetic field and solar X-ray emission (Moiseev et al., 1993). Olson et al. (1978) showed statistically that an increase of $E_{z}$, zonal circulation index, and atmospheric vortex intensity (VAI) were observed before solar flares. Doppler ionospheric sounding has shown that, 30-80 min before some X-ray flares, ionospheric disturbances having a specific waveform can be observed (Goshdzhanov et al., 1993).

Solar flares/CMEs, Ground Level Events and atmospheric disturbances

E. A. Kasatkina et al.

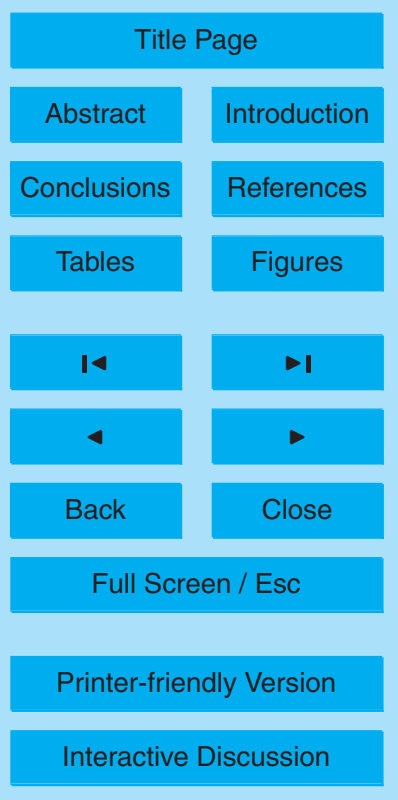

\section{7}


If these effects are connected to conductivity changes of the atmosphere, they should be connected to additional ionization sources before the solar flare or CME. As a possible solar ionization agent in the "pre-eruption" phase, one may consider UV radiation from current layers (Syrovatsky, 1977; Goshdzhanov et al., 1993) and pre-CME stream5 ers (Raymond et al., 2003), or soft X-ray emission from rising bright loops (Aurass et al., 1999; Nitta et al., 2003). For example, Syrovatsky (1977) noted the possibility of a brightness temperature increase (decrease) at radio wavelengths $\lambda<(>) 0.1 \mathrm{~m}$ in the current sheets (close to the weak solar magnetic field regions) several hours before the flare. Support for this has been provided by observations at $3.3 \mathrm{~mm}$ (Mayfield et al., 10 1970) and in the decameter wavelength range (Ramesh and Ebenezer, 2001; Ramesh et al., 2003). Syrovatsky (1977) also showed that energy in the C III (97.7 nm), OII $(83.3-84.5 \mathrm{~nm}), \mathrm{Ne}$ II $(44.5-46.2 \mathrm{~nm})$, Sill $(120.65 \mathrm{~nm})$ lines from a disturbed current sheet may be several times greater than from the undisturbed one. These conclusions have been partly supported by $\mathrm{SOHO}$ satellite observations of spectral signatures of CMEs associated with X-class flares and pre-CME streamers (Raymond et al., 2003).

However, it is difficult to suppose that UV and X-ray emissions are a possible source for the $E_{z}$ perturbations observed, except for that on 15 April 2001 which was the only event detected during the daytime, the other two being at dawn and dusk, respectively. Analysis of the LASCO SOHO (C2) Coronograph pre-event (11:54 UT) and event (13:54 UT and 14:06 UT) images (Fig. 4, from http://lasco-www.nrl.navy.mil/ cmelist.html) showed a so-called pre-CME streamer with a cavity and loop core, which appeared at 11:30 UT (approximately the time that the marked changes of $E_{z}$ began) and which rapidly disrupted just before the SF/CME event itself. Such pre-CME streamers seem to appear before CME events and may be responsible for variations in UV emission and the generation of type III radio bursts excited by electron beams (Aurass et al., 1999; Bastian et al., 2001; Raymond et al., 2003). Enhancements of the energetic $(>1 \mathrm{MeV})$ proton flux were observed at approximately 12:20 UT and $\sim 19: 00$ UT (see Fig. 1).

\section{ACPD}

9, 21941-21958, 2009

Solar flares/CMEs, Ground Level Events and atmospheric disturbances

E. A. Kasatkina et al.

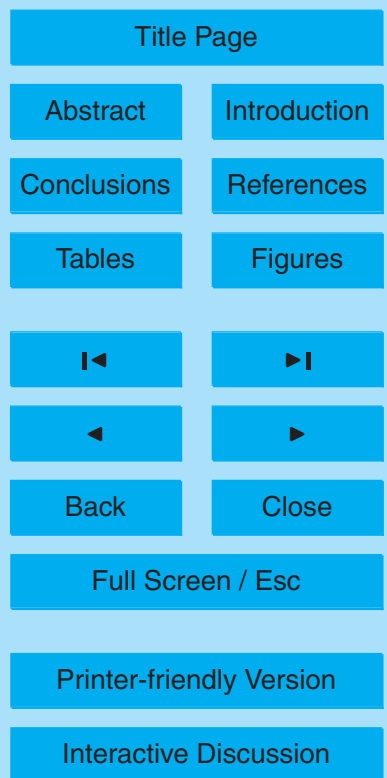


It has been reported earlier that CME-driven shocks may accelerate both protons and electrons (Haggerty and Roelof, 2002; Simnett et al., 2002; Gopalswamy et al., 2003; Kahler and Reames, 2003). Moreover, charged particle events associated with CMEs have their highest intensity below $20 \mathrm{MeV}$ (Cane et al., 2003; Perrone et al., 5 2004). As for the 4 November 2001 SF/CME event, the ejection occurred over a large part of an S-shaped active region (Nitta et al., 2003). It had an extended "pre-eruption" phase in which the structure involved expanded on timescales of some tens of minutes (Nitta et al., 2003). It had earlier been reported that CMEs usually begin to lift off from the Sun before any substantial flaring activity has occurred (Harrison et al., 1990; 10 Gosling, 1993).

\section{Conclusions}

We suppose that the $E_{z}$ disturbances observed are caused by solar energetic (with energies exceeding a few $\mathrm{MeV}$ ) charged particles (electrons and protons) associated with the CME formation. These very energetic (relativistic) particles may gain direct 15 entry into the polar caps, or be trapped in the magnetosphere and precipitate into the atmosphere (Shumilov et al., 1993). An exception is the 18 April 2001 event, when the $E_{z}$ variations seem to result from the SSC-associated particle energization which occurred at 00:42 UT on 18 April 2001 (see Fig. 2). This SSC-event was caused by the interaction of an interplanetary shock associated with the 15 April 2001 solar flare.

20 Some studies (Blake et al., 1992; Li et al., 1993) have reported injections of electrons and protons with energies above $15 \mathrm{MeV}$ into the inner magnetosphere $(2<\mathrm{L}<3)$ during such SSC-events. Goldberg et al. (1994) showed that relativistic electrons of $>1 \mathrm{MeV}$ can modulate the electrical properties of the middle atmosphere to altitudes below $50 \mathrm{~km}$.

25 In general, from a physical point of view one may note that the pre-SF/CME atmospheric $E_{z}$ disturbances may be explained by a number of different effects such as the different locations of the active region relative to the solar equator and limb, the relative
Solar flares/CMEs, Ground Level Events and atmospheric disturbances

E. A. Kasatkina et al.

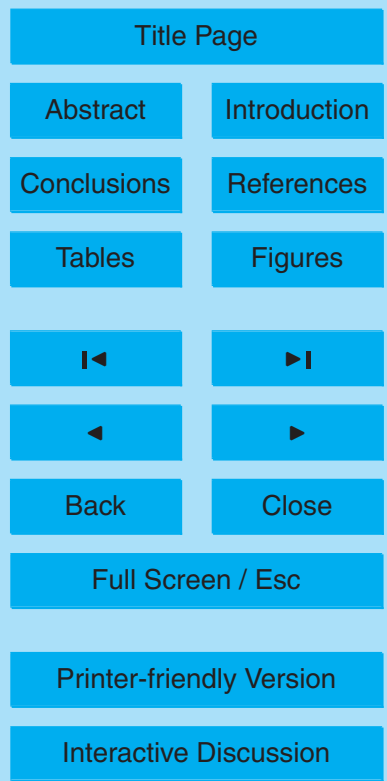


Sun-Earth position, conditions in interplanetary space, the state of the ionosphere and of the atmosphere at middle and high latitudes. What is clear, however, is that in a solar active region there are some changes in its magnetic state (the "precursor", or pre-eruption, phase) before the sharp release of the energy in form of a solar flare 5 (Mayfield et al., 1970; Syrovatsky, 1977; Ramesh and Ebenezer, 2001; Nitta et al., 2003; Raymond et al., 2003), which may also increase the electrical conductivity of the atmosphere and hence cause a reduction of $E_{z}$.

Acknowledgements. We are grateful to our colleagues from the Polar Alpine Garden-Institute of Kola Science Center RAS for meteorological data. We acknowledge the use of the CME 10 catalog of the Catholic University of America. We thank also the LASCO science team, the GOES science team and the Oulu Cosmic Ray Station for the use of their data. This work was partially supported by the Russian Foundation for Basic Research (grant N 09-04-98801), by the Program of the Russian Academy of Sciences and by the Regional Scientific Program of Murmansk Region.

\section{References}

Aikin, A. C. and Maynard, N. C.: A Van de Graff source mechanism for middle atmospheric vertical electric fields, J. Atmos. Terr. Phys., 52, 695-705, 1990.

Arnold, F.: Ion nucleation - a potential source for stratospheric aerosols, Nature, 299, 134-137, 1982.

20 Aurass, H., Vourlidas, A., Andrews, M. D., Thompson, B. J., Howard, R. H., and Mann, G.: Nonthermal radio signatures of coronal disturbances with and without coronal mass ejections, Astrophys. J., 511, 451-465, 1999.

Bastian, T. S., Pick, M., Kerdraon, A., Maia, D., and Vourlidas, A.: The coronal mass ejection of 20 April 1998: Direct imaging at radio wavelengths, Astrophys. J., 558, L65-L69, 2001.

25 Blake, J. B., Kolasinski, W. A., Fillius, R. W., and Mullen, E. G.: Injection of electrons and protons with energies of tens of MeV into $L<3$ on 24 March 1991, Geophys. Res. Lett., 19, 821-824, 1992.

Cane, H. V., von Rosenvinge, T. T., Cohen, C. M. S., and Mewaldt, R. A.: Two components in major solar particle events, Geophys. Res. Lett., 30, 8017-8020, 2003.

Solar flares/CMEs, Ground Level Events and atmospheric disturbances

E. A. Kasatkina et al.

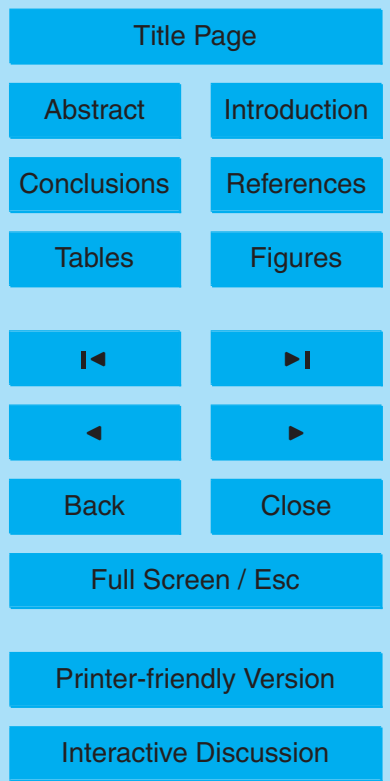


Cobb, W. E.: Evidence of a solar influence on the atmospheric electric elements at Mauna Loa Observatory, Mon. Weather Rev., 95, 905-911, 1967.

Daniljchenko, D. P., Zemlyankin, G. I., Chernysheva, S. P., and Sheftel, V. M.: On the data selection for the analysis of auroral effects in the geoelectric field, Geomagn. Aeron., 18, 1121-1125, 1978 (in Russian).

Goldberg, R. A.: Middle atmospheric electrodynamics: status and future, J. Atmos. Terr. Phys., 46, 1083-1101, 1984.

Goldberg, R. A., Baker, D. N., Herrero, F. A., McCarthy, S. P., and Twigg, P. A.: Energy deposition and middle atmosphere electrodynamic response to a highly relativistic electron 10 precipitation event, J. Geophys. Res., 99, 21071-21081, 1994.

Gopalswamy, N., Yashiro, S., Lara, A., Kaiser, M. L., Thompson, B. J., Gallagher, P. T., and Howard, R. A.: Large solar energetic particle events of cycle 23: A global view, Geophys. Res. Lett., 30, 8015-8018, 2003.

Goshdzhanov, M., Muradov, A., and Boltaev, D.: Wave-form ionospheric disturbances preced15 ing solar flares, Geomagn. Aeron., 33, 174-177, 1993 (in Russian).

Gosling, J. T.: The solar flare myth, J. Geophys. Res., 98, 18937-18949, 1993.

Haggerty, D. K. and Roelof, E.C.: Impulsive near-relativistic solar electron events: Delayed injection with respect to solar electromagnetic emission, Astrophys. J., 579, 841-853, 2002.

Hale, L. C. and Croskey C. L.: An auroral effect on the fair weather electric field, Nature, 278, 239-241, 1979.

Hofmann, D. J. and Rosen, J. M.: Condensation nuclei events at $30 \mathrm{~km}$ and possible influences of solar cosmic rays, Nature, 302, 511-514, 1983.

Holzworth, R. and Mozer, F. S.: Direct evidence of solar flare modification of stratospheric electric fields, J. Geophys. Res., 84, 2559-2566, 1979.

Holzworth, R., Norville, K. W., and Williamson, P. R.: Solar flare perturbations in stratospheric current systems, Geophys. Res. Lett., 14, 852-855, 1987.

Kahler, S. W. and Reames, D. W.: Solar energetic particle production by coronal mass ejectiondriven shocks in solar fast-wind regions, Astrophys. J., 584, 1063-1070, 2003.

Kasatkina, E. A. and Shumilov, O. I.: Cosmic ray-induced stratospheric aerosols: A possible connection to polar ozone depletions, Ann. Geophys., 23, 675-679, 2005, http://www.ann-geophys.net/23/675/2005/.

Kobrin, M. M., Malygin, V. I., and Snegirev, S. D.: On the influence of preflare pulsations of solar origin on the Earth's magnetosphere, Geomagn. Aeron., 22, 156-161, 1982 (in Russian).

\section{Solar flares/CMEs, Ground Level Events and atmospheric disturbances}

E. A. Kasatkina et al.

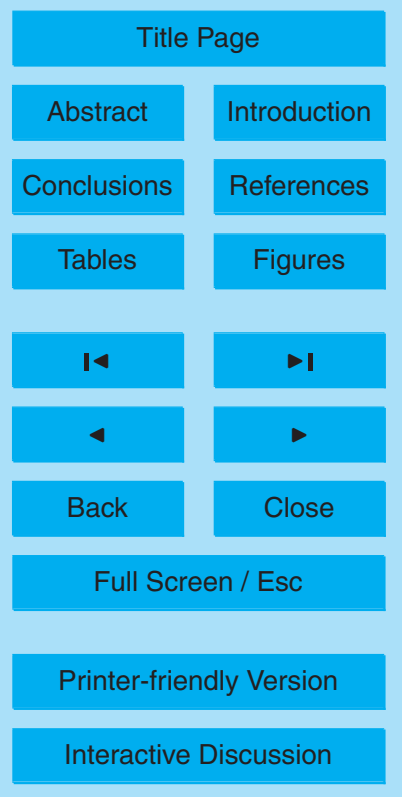


Li, X., Roth, I., Temerin, M., Wygant, J.R., Hudson, M. K., and Blake, J. B.: Simulation of the prompt energization and transport of radiation belt particles during the March 24, 1991 SSC, Geophys. Res. Lett., 20, 2423-2426, 1993.

Marcz, F.: Links between atmospheric electricity and ionospheric absorption due to extraterrestrial influences, J. Geophys. Res., 81, 4566-4570, 1976.

Marcz, F.: Short-term changes in atmospheric electricity associated with Forbush decreases, J. Atmos. Sol.-Terr. Phys., 59, 975-982, 1997.

Marcz, F. and Harrison, R. G.: Long-term changes in atmospheric electrical parameters observed at Nagycenk (Hungary) and the UK observatories at Eskdalemuir and Kew, Ann.

10 Geophys., 21, 2193-2200, 2003, http://www.ann-geophys.net/21/2193/2003/.

Markson, R.: Solar and lunar modulation of geophysical parameters, atmospheric electricity and thunderstorms, Pure Appl. Geophys., 84, 161-200, 1971.

Markson, R.: Solar modulation of atmospheric electrification and possible implications for the Sun-weather relationship, Nature, 273, 103-109, 1978.

Mayfield, E. B., Higman, J., and Samson, C.: Variations in solar emission at $3.3 \mathrm{~mm}$ wavelength and their relation to flares, Sol. Phys., 13, 372-388, 1970.

Moiseev, V. G., Murzaeva, N. N., Skryabin, N.G., and Ivanov, O. P.: Solar flare influence on electric parameters of the atmosphere, Geomagn. Aeron., 33, 113-119, 1993 (in Russian).

Nitta, N. V., Cliver, E. W., and Tylka, A. J.: Low coronal signatures of large solar energetic particle events, Astrophys. J., 586, L103-L106, 2003.

Nolte, J. T. and Roelof, E. C.: Large-scale structure of the interplanetary medium. I: High coronal source longitude of the quiet-time solar wind, Sol. Phys., 33, 241-257, 1973a.

Nolte, J. T. and Roelof, E. C.: Large-scale structure of the interplanetary medium. II: Evolving magnetic configurations deduced from multi-spacecraft observations, Sol. Phys., 33, 483504, 1973b.

Olson, R. H., Roberts, W. O., Prince, H. D., and Hedeman, E. R.: Solar plages and the vorticity of the Earth's atmosphere, Nature, 274, 140-142, 1978.

Perrone, L., Alfonsi, L., Romano, V., and de Franceschi, G.: Polar cap absorption events of November 2001 at Terra Nova Bay, Antarctica, Ann. Geophys., 22, 1633-1648, 2004,

30 http://www.ann-geophys.net/22/1633/2004/.

Poirier, J. and D'Andrea, C.: Ground level muons in coincidence with the solar flare of 15 April 2001, J. Geophys. Res., 107(A11), 1376, doi:10.1029/2001JA009187, 2002.

Ramesh, R. and Ebenezer, E.: Decameter wavelength observations of an absorption burst

Solar flares/CMEs, Ground Level Events and atmospheric disturbances

E. A. Kasatkina et al.

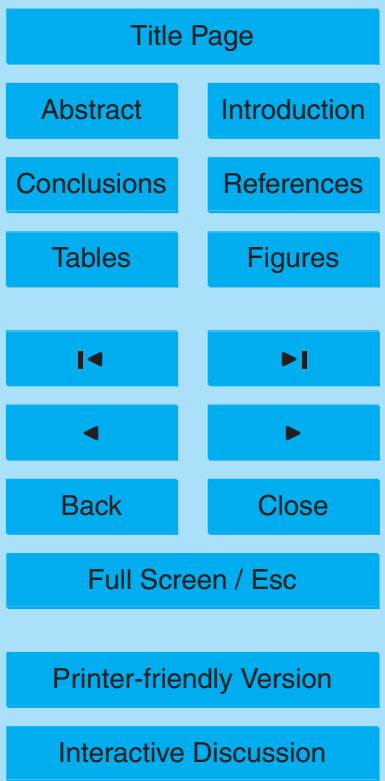


from the Sun and its association with an X2.0/3B flare and the onset of a "Halo" coronal mass ejection, Astrophys. J., 558, L141-L143, 2001.

Ramesh, R., Kathiravan, C., and Sastry, Ch. V.: Metric radio observations of the evolution of a "Halo" coronal mass ejection close to the Sun, Astrophys. J., 591, L163-L166, 2003.

5 Raymond, J. C., Ciaravella, A., Dobrzycka, D., Strachan, L., Ko, Y.-K., Uzzo, M., and Raouafi, N.-E.: Far-Ultraviolet spectra of fast coronal mass ejections associated with X-class flares, Astrophys. J., 597, 1106-1117, 2003.

Reagan, J. B., Meyerott, R. E., Evans, J. E., Imhof, W. L., and Joiner, R. G.: The effects of energetic particle precipitation on the atmospheric electric circuit, J. Geophys. Res., 88, $10 \quad 3869-3878,1983$.

Reiter, R.: Solar flares and their impact on potential gradient and air-earth current characteristics at high mountain stations, Pure Appl. Geophys., 72, 259-267, 1969.

Rycroft, M. J., Israelsson, S., and Price, C.: The global atmospheric electric circuit, solar activity and climate change, J. Atmos. Sol. Terr. Phys., 62, 1563-1576, 2000.

Sheftel, V. M., Bandilet, O. I., Yaroshenko, A. N., and Chernyshev, A. K.: Space-time structure and reasons of global, regional, and local variations of atmospheric electricity, J. Geophys. Res., 99, 10797-10806, 1994.

Shumilov, O. I., Vashenyuk E. V., and Henriksen, K.: Quasi-drift effects of high-energy solar cosmic rays in the magnetosphere, J. Geophys. Res., 98, 17423-17427, 1993.

20 Shumilov, O. I., Kasatkina, E. A., Henriksen, K., and Vashenyuk, E. V.: Enhancement of stratospheric aerosols after solar proton event, Ann. Geophys., 14, 1119-1123, 1996, http://www.ann-geophys.net/14/1119/1996/.

Simnett., G. M., Roelof, E. C., and Haggerty, D. K.: The acceleration and release of nearrelativistic electrons by coronal mass ejections, Astrophys. J., 579, 854-862, 2002.

Solar Geophysical Data Reports: NOAA Solar Geophysical Data Reports for April, National Geophysical Data Center, Boulder, Colorado, 2001.

Syrovatskij, S. I.: On the possibility to observe preflare current sheets on the Sun, Astrophys. J. Lett., 3, 133-137, 1977 (in Russian).

Zadorozhny, A. M., Kikhtenko, V. N., Kokin, G. A., Tuchkov, G. A., Tyutin, A. A., Chizov, A. F., and Shtirkov, O. V.: Middle atmosphere response to the solar proton events of October 1989 using the results of rocket measurements, J. Geophys. Res., 99, 21059-21069, 1994.

Zadorozhny, A. M. and Tyutin, A. A.: Effects of geomagnetic activity on the mesospheric electric fields, Ann. Geophys., 16, 1544-1551, 1998, http://www.ann-geophys.net/16/1544/1998/.

\section{Solar flares/CMEs, Ground Level Events and atmospheric disturbances}

E. A. Kasatkina et al.

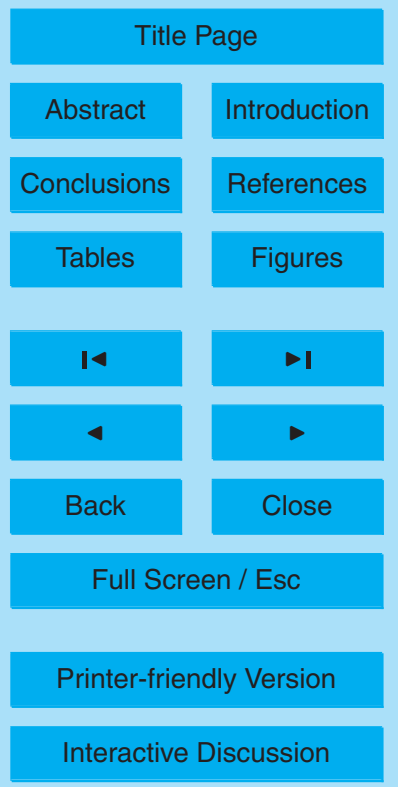




\section{ACPD}

9, 21941-21958, 2009

Solar flares/CMEs, Ground Level Events and atmospheric disturbances

Table 1. Flare/CME events associated with SPEs and observed by SOHO/LASCO.

\begin{tabular}{clllllll}
\hline Date & $\begin{array}{l}\text { Flare } \\
\text { Start } \\
(\mathrm{UT})\end{array}$ & $\begin{array}{l}\text { Flare } \\
\text { Intensity }\end{array}$ & $\begin{array}{l}\text { Flare } \\
\text { Location }\end{array}$ & $\begin{array}{l}\text { CME } \\
\text { onset } \\
(\mathrm{UT})\end{array}$ & $\begin{array}{l}\text { SPE } \\
\text { Start } \\
(\mathrm{UT})\end{array}$ & $\begin{array}{l}\text { SPE } \\
\text { Peak } \\
(\mathrm{UT})\end{array}$ & $\begin{array}{l}\text { >10 MeV Proton } \\
\text { Flux at SPE peak } \\
\left(\mathrm{cm}^{-2} \mathrm{sr}^{-1} \mathrm{~s}^{-1} \mathrm{MeV}^{-1}\right)\end{array}$ \\
\hline 15 Apr 2001 & $13: 19$ & X14 & S20 W85 & $13: 32$ & $14: 10$ & $19: 20$ & 951 \\
18 Apr 2001 & $02: 14$ & C2 & S20W-Limb & $02: 11$ & $03: 15$ & $10: 45$ & 321 \\
4 Nov 2001 & $16: 03$ & X1.0 & N06 W18 & $16: 12$ & $17: 05$ & $06 / 02: 15$ & 31700 \\
\hline
\end{tabular}

E. A. Kasatkina et al.

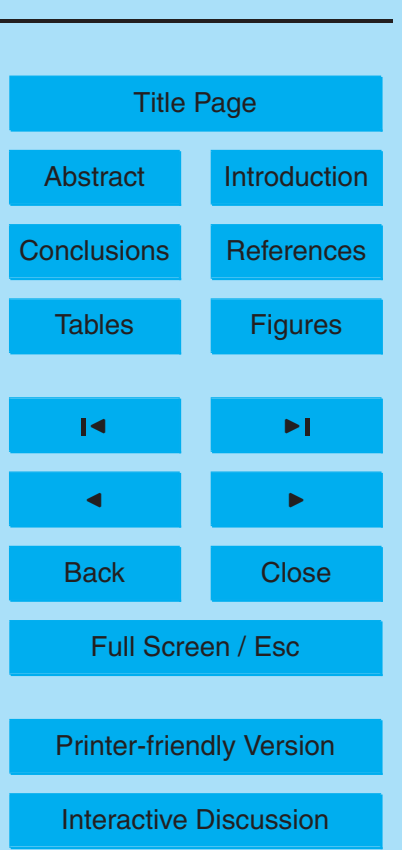




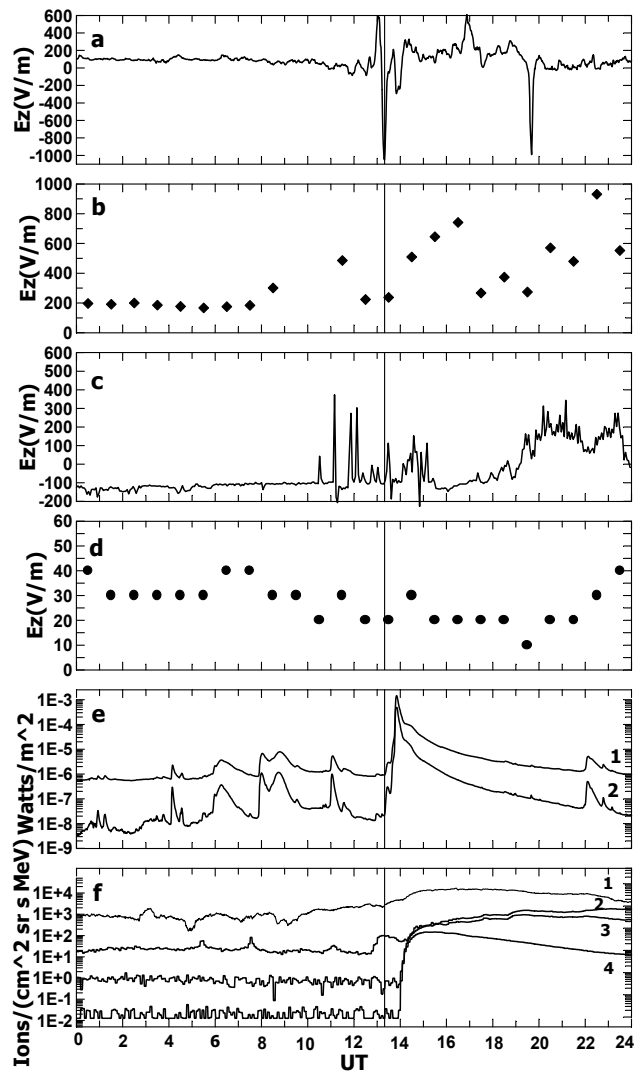

\section{Solar flares/CMEs, Ground Level Events and atmospheric disturbances}

E. A. Kasatkina et al.

Fig. 1. For the 15 April 2001 GLE: (a) records of the vertical component of the atmospheric electric field $\left(E_{z}\right)$ at Apatity (geomagnetic latitude $\left.\Lambda=63.3^{\circ}\right)$; (b) Vostok $\left(\Lambda=-89.3^{\circ}\right)$; (c) Voeikovo $\left(\Lambda=56.1^{\circ}\right)$; (d) Nagycenk $\left(\Lambda=47.2^{\circ}\right)$; (e) GOES X-ray fluxes (1 for the $0.1-0.8 \mathrm{~nm}$, and 2 for the $0.0-0.4 \mathrm{~nm}$ wavelength bands); (f) 1 - $\mathrm{min}$ flux values of electrons with $E>2 \mathrm{MeV}-1$, protons with $\mathrm{E}>1 \mathrm{MeV}-2$, protons with $\mathrm{E}>10 \mathrm{MeV}-3$, and protons with $\mathrm{E}>100 \mathrm{MeV}-4$. The moment of flare onset is shown by the vertical line at 13:19 UT.

Title Page

Abstract

Introduction

Conclusions

References

Tables

Figures

14

$\rightarrow$

4

Back

Close

\section{Full Screen / Esc}

Printer-friendly Version

Interactive Discussion 


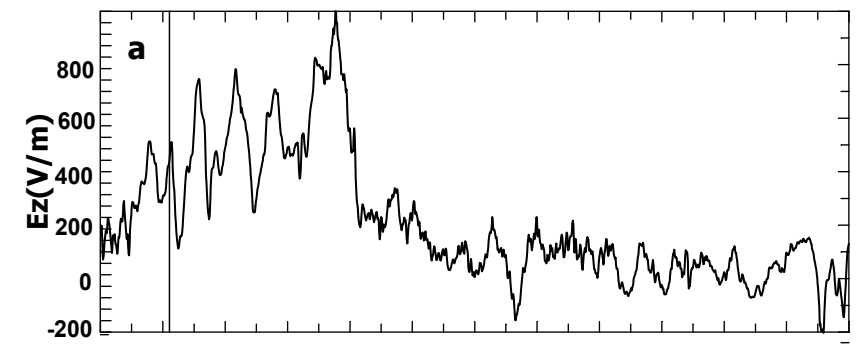

ACPD

9, 21941-21958, 2009

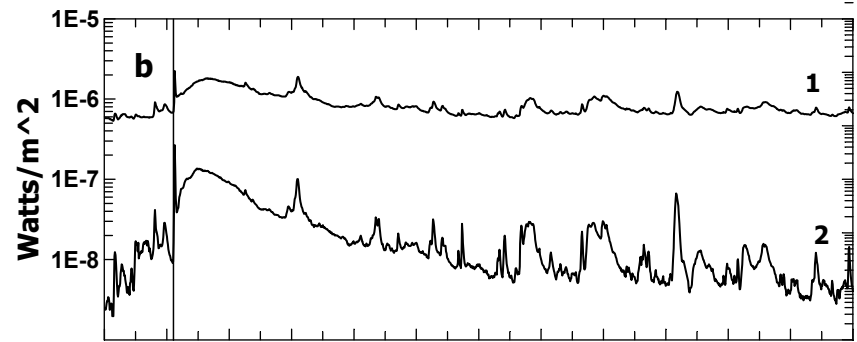

Solar flares/CMEs, Ground Level Events and atmospheric disturbances

E. A. Kasatkina et al.

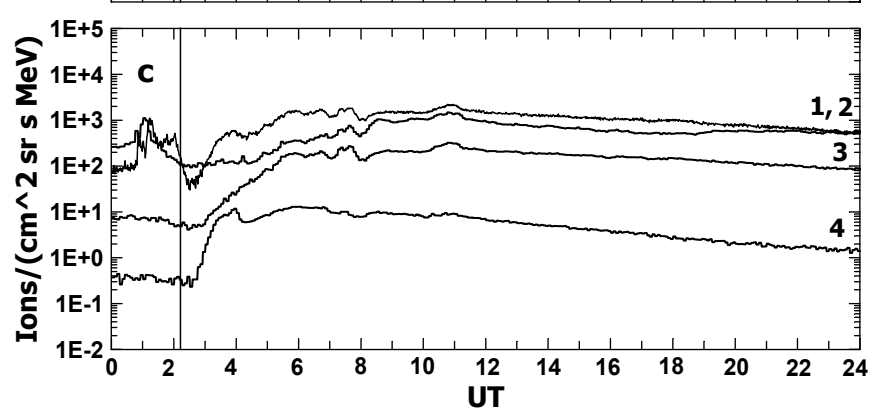

Title Page

Abstract Introduction

Conclusions

References

Tables

Figures

14

$\rightarrow$

4

Back

Close

Full Screen / Esc

Fig. 2. For the 18 April 2001 GLE: (a) records of the vertical component of the atmospheric electric field $\left(E_{z}\right)$ at Apatity; (b) GOES X-ray fluxes (1 for the $0.1-0.8 \mathrm{~nm}$, and 2 for the $0.05-$ $0.4 \mathrm{~nm}$ wavelength bands); (c) 1 -min flux values of electrons with $\mathrm{E}>2 \mathrm{MeV}-1$, protons with $\mathrm{E}>1 \mathrm{MeV}-2$, protons with $\mathrm{E}>10 \mathrm{MeV}-3$, and protons with $\mathrm{E}>100 \mathrm{MeV}$. The moment of flare onset is shown by the vertical line at 02:14 UT. 


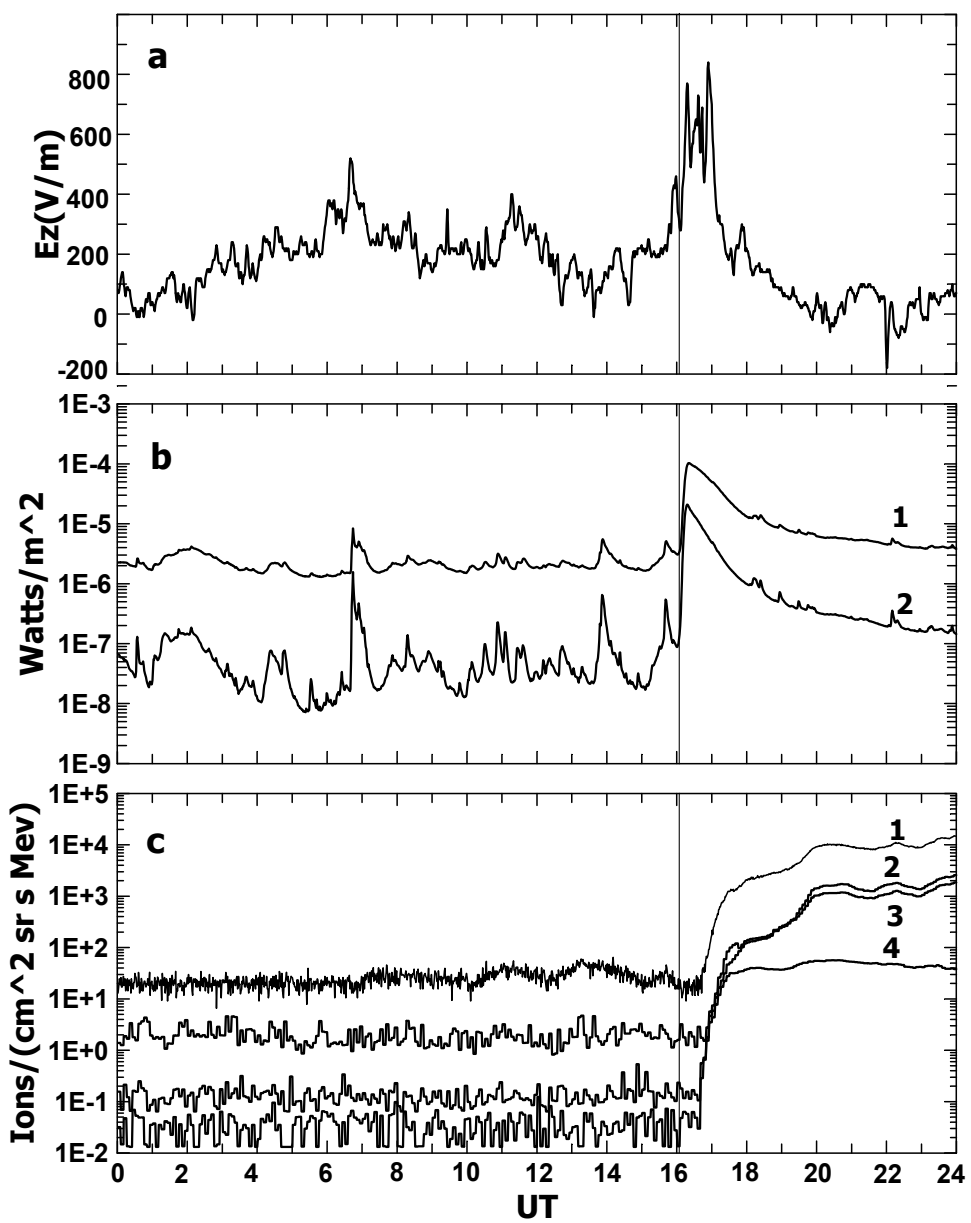

9, 21941-21958, 2009

Solar flares/CMEs, Ground Level Events and atmospheric disturbances

E. A. Kasatkina et al.

Title Page

Abstract

Introduction

Conclusions

References

Tables

Figures

14

-

4

Back

Close

Full Screen / Esc

Printer-friendly Version

Interactive Discussion

Fig. 3. The same as for Fig. 2 but for the 4 November 2001 GLE. 


\section{ACPD}

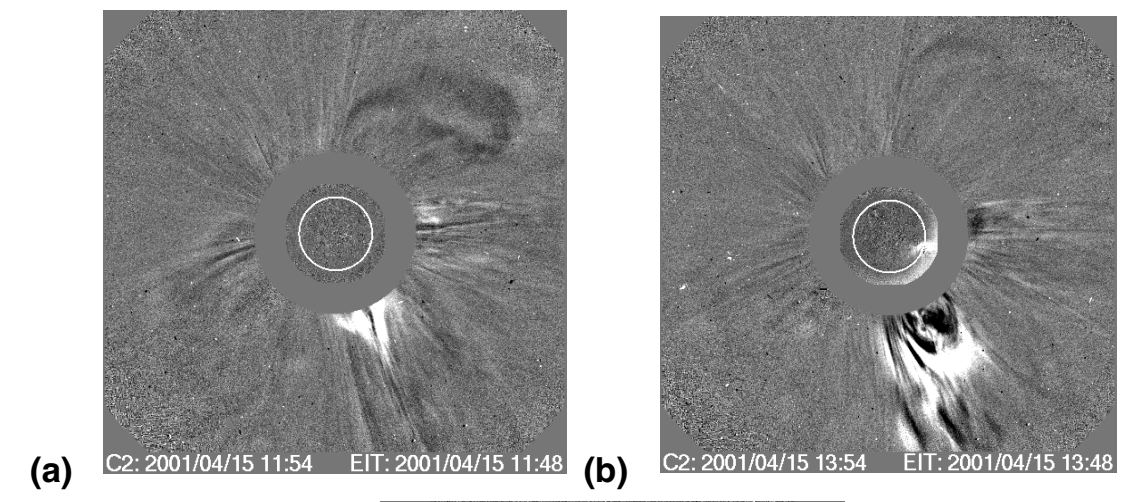

9, 21941-21958, 2009

\section{Solar flares/CMEs, Ground Level Events and atmospheric disturbances}

E. A. Kasatkina et al.

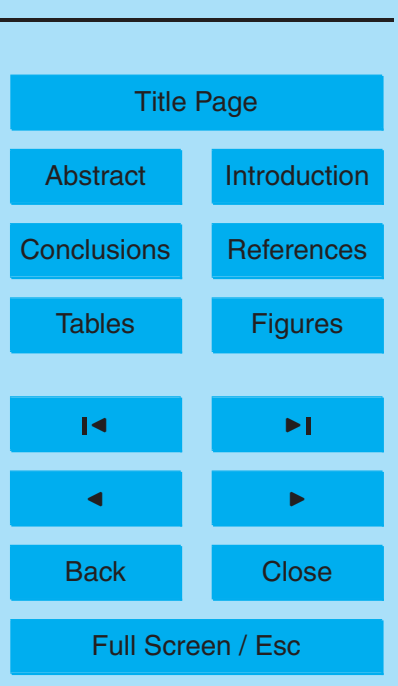

Fig. 4. Consecutive phases of the 15 April 2001 SF/CME event development evident from the data of LASCO SOHO (C2) coronograph images: (a) pre-event (11:54 UT), (b) early in the event (13:54 UT) and (c) peak of the event(14:06 UT).

Printer-friendly Version

Interactive Discussion 